\title{
Communication practices and awareness of resources for acromegaly patients among endocrinologists
}

\author{
Susan Polanco-Briceno' \\ Daniel Glass' \\ Cindy Plunkett ${ }^{2}$ \\ 'Deerfield Institute, New York, \\ NY, USA; ${ }^{2}$ Department of Internal \\ Medicine, Metabolism Endocrinology \\ \& Diabetes (MEND), University of \\ Michigan, Ann Arbor, MI, USA
}

This article was published in the following Dove Press journal:

Patient Preference and Adherence

14 December 2016

Number of times this article has been viewed

Correspondence: Susan Polanco-Briceno Deerfield Institute, 780 Third Avenue, 37th floor, New York, NY 10017 , USA $\mathrm{Tel}+\mid$ 2I2 55I I600

Email spolanco-briceno@deerfield.com
Purpose: This study was designed to assess the awareness and utilization of resources to improve patients' treatment experiences among endocrinologists who currently treat patients with acromegaly.

Methods: A total of 4,280 US endocrinologists were randomly selected from the CMS National Plan and Provider Enumeration System and were invited by mail to participate in a 20-minute online survey. In order to qualify, respondents had to be the primary physician making treatment decisions for at least one patient for their acromegaly.

Results: Results are based on responses from 126 physicians from primarily urban and suburban practices, with a median of five acromegaly patients. A total of $70 \%$ of patients are currently receiving drug therapy; among these, $91 \%$ are on octreotide $(51 \%)$, lanreotide $(29 \%)$, or pasireotide $(11 \%)$, alone or in combination with another therapy. Nearly half of the respondents thought that the impact of patient adherence on therapy outcome for acromegaly was either not very $(40 \%)$ or not at all (7\%) significant. Respondents who believe patient adherence significantly impacts treatment outcome were significantly more likely to discuss automated adherence reminders ( $50 \%$ vs $26 \% ; P=0.015)$, mobile administration programs $(57 \%$ vs $35 \%$; $P=0.029$ ), and symptom tracking ( $72 \%$ vs $42 \% ; P=0.002)$. Overall, $44 \%$ of respondents routinely recommend education/emotional support programs, and $25 \%$ routinely recommend financial assistance programs. Respondents who believe patient adherence significantly impacts treatment outcome generally were more familiar with individual education and emotional support programs compared to those who do not, although they were not more likely to routinely refer patients to any of these resources.

Conclusion: There are unmet needs with respect to increasing awareness among physicians of the importance of patient adherence to therapy, resources available to patients, and how collaboration among patients, nurses, and physicians can improve adherence and overall treatment experiences.

Keywords: financial support programs, emotional support programs, referrals

\section{Introduction}

Acromegaly, a complex disorder caused by hypersecretion of growth hormone by somatotrophs in the pituitary gland, often due to a pituitary tumor, ${ }^{1,2}$ is associated with significantly impaired quality of life (QoL). ${ }^{3}$ Symptoms of acromegaly, which commonly include fatigue, joint pain, snoring, excessive sweating, and headaches, often interfere with daily life activities. ${ }^{1,4}$ Acromegaly-related comorbidities and complications (eg, cardiovascular disease, diabetes, cancer, kidney failure, hypothyroidism, bone/joint abnormalities, and sleep apnea) $)^{1,5-9}$ further contribute to decreased QoL ${ }^{10}$ 
and are associated with a high economic burden ${ }^{7,8}$ and increased mortality risk. ${ }^{11,12}$

Acromegaly treatment guidelines recommend the use of pharmacotherapy as adjuvant therapy in cases of persistent disease following surgery or as primary therapy in cases for which surgery is not feasible. ${ }^{13}$ Treatment is aimed at achieving a biochemical target goal of an age-normalized serum insulin-like growth factor-1 value; an additional therapeutic goal is a random growth hormone $<1.0 \mu \mathrm{g} / \mathrm{L}$, which correlates with control of acromegaly. ${ }^{13}$ Recommended treatments include somatostatin analogs (SSAs, eg, octreotide, lanreotide, or pasireotide) or pegvisomant as initial therapy in patients with significant disease, and dopamine agonists (usually cabergoline) for patients with mild to moderate disease. ${ }^{13}$ A study using claims data from a database of commercially insured patients from 2006 to 2013 found that over half of patients diagnosed with acromegaly received acromegalyspecific pharmacotherapy, with cabergoline and octreotide prescribed most frequently. ${ }^{7}$

Achieving biochemical control has been associated with reduction of symptoms and complications and reduced mortality risk and may improve QoL..$^{14,15}$ Therefore, adherence to therapy is an important component in successful longterm treatment. However, the aforementioned claims database study found that adherence rates to pharmacologic treatment were generally low $(<40 \%$ ); rates of persistence (remaining on therapy for the minimum recommended time) were also low $(<65 \%){ }^{7}$ The SSAs and pegvisomant are administered parenterally, with dosing frequency that varies from four times per day to once every 4 weeks, which may contribute to nonadherence. ${ }^{7}$ Other aspects of acromegaly treatment can be burdensome to patients, such as injection-related signs and symptoms (eg, injection-related pain, which may last several days after injection), emotional impact (eg, some patients report feeling a loss of independence), disruptions to everyday life (eg, inconvenience of transportation to and from the general practitioner's office or clinic to receive injections, work loss, and problems with preparation and administration of injections), ${ }^{4}$ or the financial burden of treatment; ${ }^{7}$ these burdens may also present barriers to adherence. Finally, some patients may independently discontinue treatment when their acromegaly symptoms appear to resolve or are mild and do not improve with therapy. ${ }^{16}$

Establishment of a partnership with health care providers is important to patients, ${ }^{17}$ and effective communication may help to improve adherence. ${ }^{18}$ In addition, a number of patient education, support, and financial resources are available for patients which may help to overcome some barriers to adherence. ${ }^{18} \mathrm{~A}$ survey was undertaken to assess communication practices, along with awareness and utilization of acromegaly-related patient resources among endocrinologists who currently treat patients with acromegaly.

\section{Materials and methods Survey design}

A national online survey was developed and administered. A total of 4,280 endocrinologists were randomly selected from the database of 8,301 endocrinologists, based on the CMS National Plan and Provider Enumeration System. United States-licensed physicians were invited by mail to participate in a 20-minute, online national survey. The topic of the survey mentioned on the invitation was generalized to treatments for acromegaly. The eligibility criteria to participate in the survey were as follows: physicians had to be the primary physicians making treatment decisions for at least one patient for their acromegaly. They also had to be willing to provide accurate responses to questions about their professional experiences. It was assumed that participation in this survey was random and represented basic interest and knowledge in acromegaly. No physician data were excluded from the analysis based on their response to the screener questions.

\section{Ethics, consent, and permissions}

Physicians were offered an industry-standard honorarium for their time to complete the survey. By opting into the survey, the respondents provided consent to use their anonymized responses to the survey questions. Because this study did not involve patients or patient data, Institutional Review Board approval and patient consent were not required.

All survey research conducted for this article was done in accordance with the ethics practices outlined by the Council of American Survey Research Organizations (CASRO). ${ }^{19}$

\section{Survey and data collection}

The survey was live from March 9, 2016, to April 5, 2016 (the survey was left open for 4 weeks and was closed once fewer than one response every 3 days was received, and once no substantial increase in number of respondents completing was expected based on previous experience), and comprised 41 quantitative and qualitative questions. Quantitative questions were asked about the following topics: the number of patients diagnosed and treated for acromegaly, treatments of acromegaly, patient communication practices, and referrals to patient education and support resources. Qualitative questions were asked about opinions on patient adherence as it relates to treatment outcomes, awareness of patient education and support resources, and satisfaction with currently 
available treatments. Additional questions not included in this analysis included questions about use of surgery and preoperative treatments, familiarity with treatment guidelines, and opinions on potential new therapies. The survey also contained a short demographic section that asked respondents to provide their gender, the number of years in practice, and the location and the setting of their practice.

\section{Data analysis}

The individual identities of physician survey respondents were blinded to the study authors. All survey data were analyzed in the aggregate. Responses to the closed questions were analyzed quantitatively. A response that addressed multiple categories was counted as multiple comments. SPSS Version 20 was used. All continuous variables were analyzed using Student's $t$-test after testing for homogeneity of variance using Levene's Test of Equality of Variances. All categorical variables for which the expected cell frequencies were $>5$ were analyzed using the Pearson chi-square test. Fisher's exact test was used whenever the expected cell frequencies were $\leq 5 . P<0.05$ was considered significant.

\section{Results}

\section{Respondents, practice information, patient information, and prescribed treatments}

Of the 146 respondents who entered the screener, 133 qualified based on currently being the primary physician making treatment decisions specifically for acromegaly for at least one patient. Results are based on 126 physicians who completed the survey at the time of the analysis. Respondents were mostly $(63 \%)$ male and in practice for a mean of 17.3 years. Urban and suburban practices were about equally represented; group practice was the most common practice type (50\%). Approximately one third of respondents reported an academic affiliation, whereas only $10 \%$ were affiliated with a pituitary center (Table 1 ).

Information regarding the respondents' acromegaly patients (ie, those for whom each respondent was the primary physician making treatment decisions) is summarized in Table 1. Respondents reported managing a median of five acromegaly patients (mean, 11.3). The majority of patients (71\%) were aged 30-59 years (data not shown). A total of $70 \%$ of patients are currently receiving drug therapy. Of these, $>90 \%$ are on octreotide $(51 \%)$, lanreotide (29\%), or pasireotide (11\%), either alone or in combination with another therapy (Figure 1A and B). The majority of patients $(64 \%)$ receive treatment at home.
Table I Respondent demographics, practice information, and prescribing information

\begin{tabular}{|c|c|}
\hline & $\begin{array}{l}\text { Total respondents } \\
(\mathrm{n}=126)\end{array}$ \\
\hline Gender, male/female & $63 \% / 37 \%$ \\
\hline Years in practice, mean (SD) & $17.3(12.4)$ \\
\hline Median (range) & $15(2-60)$ \\
\hline \multicolumn{2}{|l|}{ Practice setting } \\
\hline Urban & $49 \%$ \\
\hline Suburban & $48 \%$ \\
\hline Rural & $3 \%$ \\
\hline \multicolumn{2}{|l|}{ Practice type } \\
\hline Group practice & $50 \%$ \\
\hline Solo private practice & $22 \%$ \\
\hline Hospital-based & $17 \%$ \\
\hline Clinic & $9 \%$ \\
\hline Academic affiliation, $\mathrm{Y} / \mathrm{N}$ & $33 \% / 67 \%$ \\
\hline Affiliation with pituitary center, $\mathrm{Y} / \mathrm{N}$ & $10 \% / 90 \%$ \\
\hline \multicolumn{2}{|l|}{$\begin{array}{l}\text { Current number of acromegaly patients } \\
\text { (as primary physician) }\end{array}$} \\
\hline Mean (SD) & $11.3(17.8)$ \\
\hline Median (range) & $5(I-125)$ \\
\hline \multicolumn{2}{|l|}{ Patients personally diagnosed in the past 2 years } \\
\hline Mean (SD) & $3.3(6.7)$ \\
\hline Median (range) & $2(0-50)$ \\
\hline Diagnosed $\geq I$ patient in past 2 years & $75 \%$ \\
\hline \multirow{2}{*}{\multicolumn{2}{|c|}{$\begin{array}{l}\text { Patients referred after diagnosis by another } \\
\text { physician }\end{array}$}} \\
\hline & \\
\hline Mean (SD) & $5.4(12.8)$ \\
\hline Median (range) & $2(0-90)$ \\
\hline Had $\geq$ I patient referred & $79 \%$ \\
\hline \multirow{2}{*}{\multicolumn{2}{|c|}{$\begin{array}{l}\text { Number of patients initiated on drug therapy } \\
\text { in past } 12 \text { months }\end{array}$}} \\
\hline & \\
\hline Mean (SD) & $2.7(4.2)$ \\
\hline Median (range) & I (0-25) \\
\hline $\begin{array}{l}\text { Physicians who have initiated } \geq I \text { patient on } \\
\text { drug therapy in the past } 12 \text { months }\end{array}$ & $66 \%$ \\
\hline $\begin{array}{l}\text { Physicians who have ever initiated } \geq I \text { patient } \\
\text { on drug therapy }\end{array}$ & $94 \%$ \\
\hline \multicolumn{2}{|l|}{ Patients currently on pharmacologic therapy } \\
\hline Mean number of patients (SD) & $7.8(12.3)$ \\
\hline Median (range) & $4(0-75)$ \\
\hline Percentage of patients & $70 \%$ \\
\hline
\end{tabular}

Abbreviations: $N$, no; SD, standard deviation; $Y$, yes.

\section{Physician satisfaction with current treatments and perspective on the impact of patient adherence on therapy outcome}

A total of $48 \%$ of respondents indicated that they were very or extremely satisfied with the efficacy, and 56\% were very or extremely satisfied with the safety of currently available acromegaly treatments, but $45 \%$ and $39 \%$, respectively, were only somewhat satisfied, and $7 \%$ and $6 \%$, respectively, were not very or not at all satisfied.

Nearly half of the respondents thought that the impact of patient adherence on therapy outcome for acromegaly was either not very (41\%) or not at all (7\%) significant, whereas 
A

Octreotide monotherapy

Lanreotide monotherapy

Pasireotide monotherapy

Octreotide + any other agent(s)

Lanreotide + any other agent(s)

Pasireotide + any other agent(s)

Other*
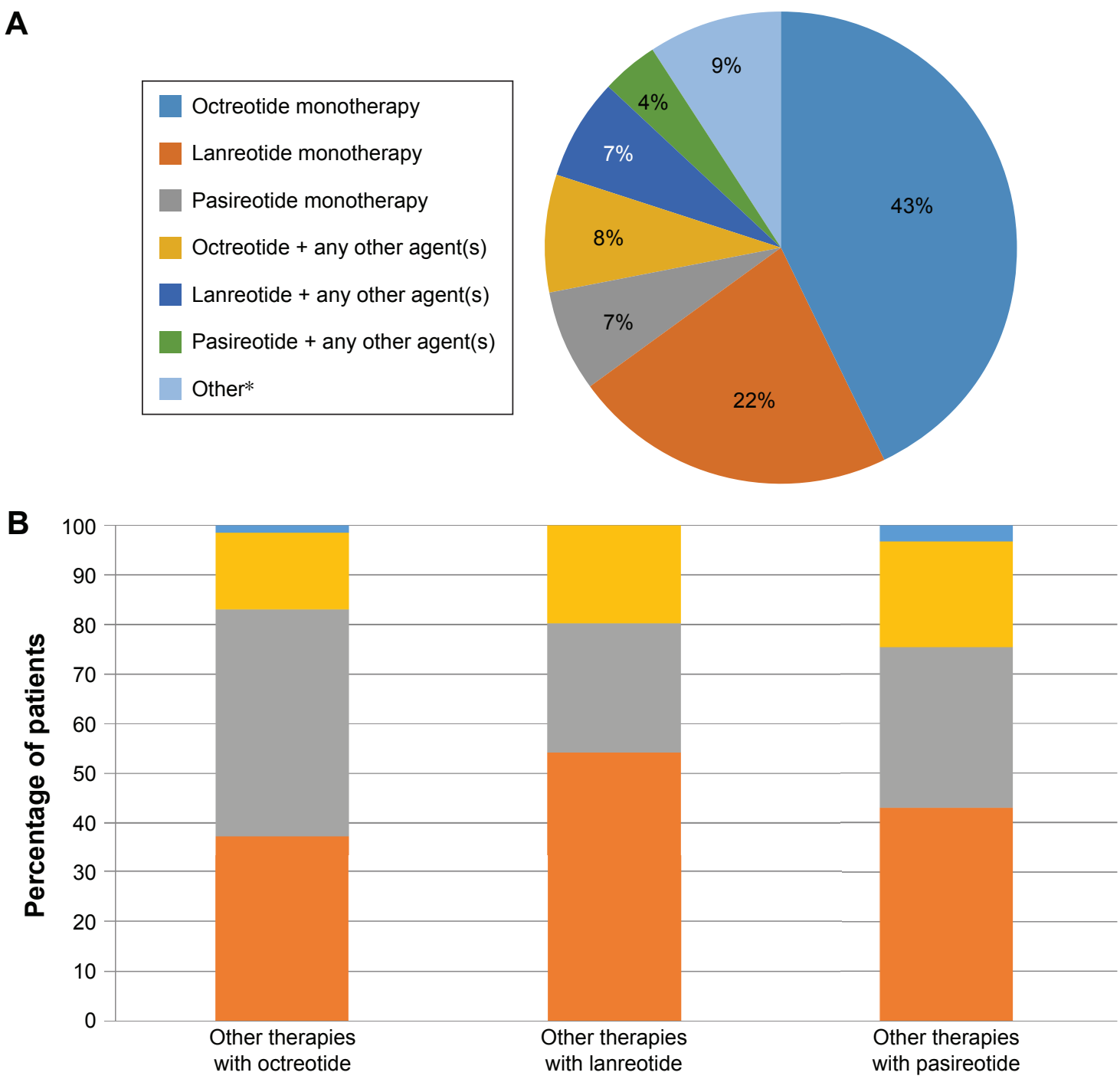

Other

Cabergoline or bromocriptine only
Both pegvisomant and cabergoline or bromocriptine

Pegvisomant only

Figure I (A) Percentage of patients receiving pharmacotherapy for acromegaly; (B) percentage of patients receiving combination therapies. Note: *Other refers to any agent(s) other than a somatostatin analog (eg, pegvisomant and cabergoline).

$42 \%$ thought it was very significant and $10 \%$ extremely significant. Responses to questions regarding communication with patients and use of patient resources were analyzed to compare the responses between the respondents who did and did not believe that patient adherence has a significant impact on outcome.

\section{Communication with patients}

Respondents indicated that $27 \%$ of patients speak with a nurse the same day they are diagnosed. However, respondents discussed a patient's support structure (either during diagnosis or when discussing treatment options) with $69 \%$ of their patients, on average (Figure 2). There was no difference in these practices between physicians who believe that patient adherence significantly impacts treatment outcome $(\mathrm{M}=31.2, \mathrm{SD}=40.5)$ and those who believe that it does not $(\mathrm{M}=22.7, \mathrm{SD}=38.7) ; \mathrm{t}(124)=1.208, P=0.229$, in terms of the proportion of patients who speak with a nurse the same day they are diagnosed. Similarly, there was no difference in these practices between physicians who believe that patient adherence significantly impacts treatment outcome $(\mathrm{M}=71.0, \mathrm{SD}=38.1)$ and those who believe that it does not $(\mathrm{M}=67.2, \mathrm{SD}=38.9) ; \mathrm{t}(124)=0.556, P=0.480$, in terms of the proportion of patients with whom they discussed a patient's support structure (either during diagnosis or when discussing treatment options). 


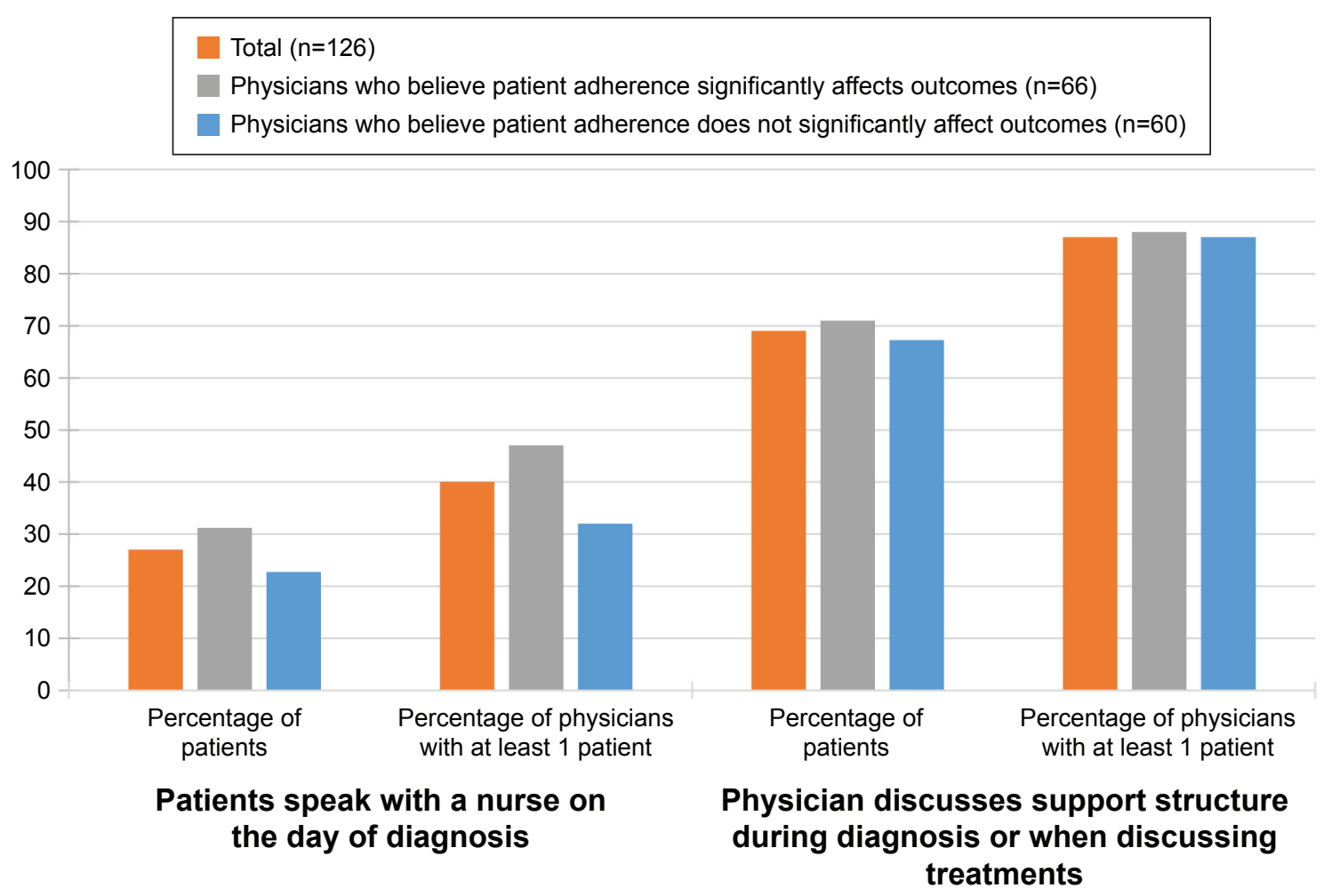

Figure 2 Frequency of speaking with nurses and discussion of support structure.

Notes: No difference between physicians who do and do not believe that patient adherence significantly impacts treatment outcome in terms of the proportion of patients who speak with a nurse the same day they are diagnosed $(\mathrm{t}[124]=1.208, P=0.229)$ and no difference in terms of the proportion of patients with whom they discussed support structure $(\mathrm{t}[124]=0.556, P=0.480)$.

The survey also explored the degree to which physicians recommend programs or practices that may improve patient adherence - automated adherence reminders, a mobile administration program that allows health care providers to deliver injections at home or a convenient location, or a diary for symptom tracking - including whether there is a dedicated nurse who discusses these topics with patients (Table 2). Most physicians did not have a dedicated nurse to discuss these topics ( $24 \%$ mentioned for automated adherence reminders, $17 \%$ for the mobile administration program, and $14 \%$ for symptom tracking). There was only a marginal difference between physicians who do or do not believe patient adherence significantly impacts treatment outcome with regard to the percentage having a dedicated nurse to discuss automated adherence reminders: $X^{2}$ $(1, \mathrm{~N}=126)=3.22, P=0.073$, and symptom tracking, $X^{2}(1$, $\mathrm{N}=126)=3.31, P=0.069$. There was no significant difference between these groups with regard to the percentage having a dedicated nurse to discuss the mobile administration program, $X^{2}(1, \mathrm{~N}=126)=0.481, P=0.488$. Among physicians without a dedicated nurse, those who believe patient adherence significantly impacts treatment outcome were significantly more likely to, 1) discuss automated adherence reminders (eg, e-mails, phone calls, letters, and text messages) (50\% vs $\left.26 \%, X^{2}[1, \mathrm{~N}=96]=5.888, P=0.015\right) ; 2$ ) discuss the mobile administration program $\left(57 \%\right.$ vs $35 \% ; X^{2}[1, \mathrm{~N}=104]=4.749$, $P=0.029$ ); and 3 ) discuss symptom tracking ( $72 \%$ vs $42 \%$; $\left.X^{2}[1, \mathrm{~N}=108]=9.804, P=0.002\right)$.

\section{Awareness and referrals by physicians to patient education/emotional support programs}

Only $14 \%$ of the respondents indicated that they routinely recommend education/emotional support programs to patients; however, after being presented with a list of nine examples of education/emotional support programs, this increased to $44 \%$, with $40 \%$ being familiar with at least one (though not routinely referring patients to any), and $17 \%$ not familiar with any (Figure 3A). There was no significant difference between the respondents who believe that patient adherence significantly impacts treatment outcome and those who do not in the proportion who routinely refer patients to at least one program, the proportion familiar with at least one program, and the proportion being familiar with any program; $X^{2}(2, \mathrm{~N}=126)=0.654, P=0.721$. Top patient education and emotional support resources physicians refer 


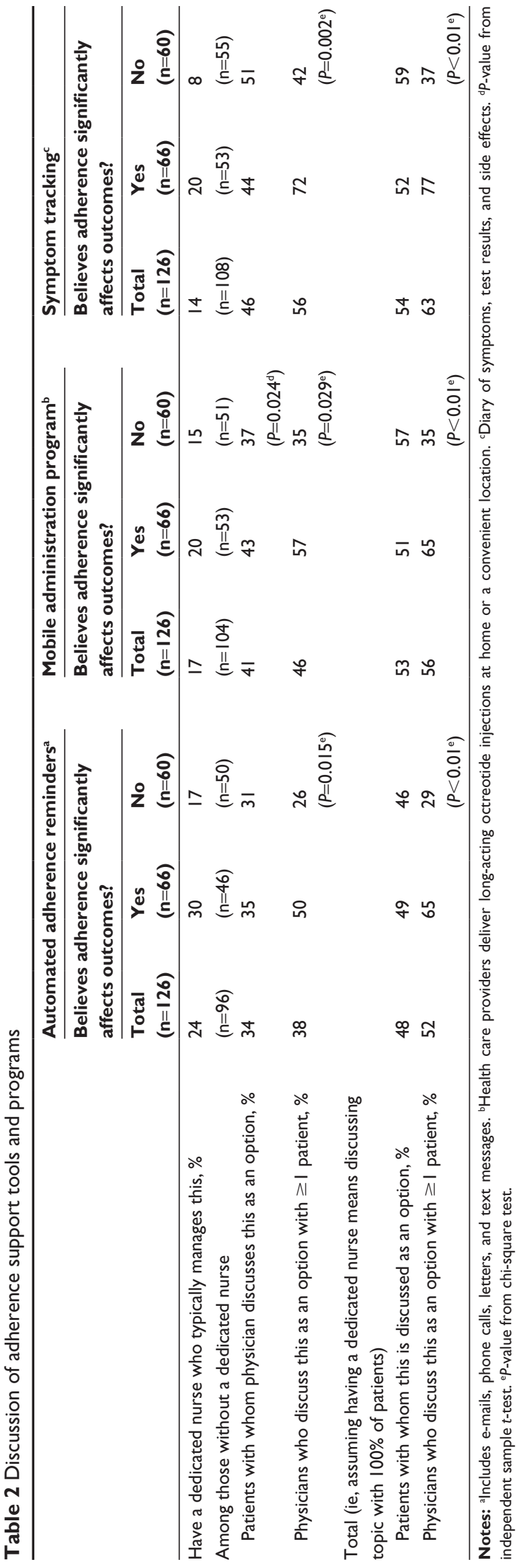

patients to "Hormone Health Network (www.hormone.org)" and "Pituitary Network Association (www.pituitary.org)," with $21 \%$ of respondents referring patients to each of these (Figure 3B). An additional 37\% are familiar with "Hormone Health Network," but are not routinely referring patients to it, versus an additional $18 \%$ familiar with "Pituitary Network Association," but not routinely referring patients to it. Furthermore, 44\% mention being familiar with "Pituitary Society (www.pituitary-society.org)" although only 9\% routinely refer patients to this. Overall, respondents who believe that patient adherence significantly impacts treatment outcome were more familiar with individual education and emotional support programs compared to those who do not, although they were generally not more likely to routinely refer patients to any of these resources. There was a significant difference in familiarity with "Acromegaly Info (www. acromegalyinfo.com)" ( $P=0.015$, Fisher's exact test $)$ and "Pituitary Disorders (www.pituitarydisorder.net)" $\left(X^{2}[2\right.$, $\mathrm{N}=126]=8.769, P=0.012$ ); physicians who believe that patient adherence significantly impacts treatment outcome were significantly more likely than those who do not to be familiar with both resources (33\% vs 17\% familiar with "Acromegaly Info," respectively, and 35\% vs 18\% familiar with "Pituitary Disorders," respectively), although there was no difference in routine referrals $(11 \%$ vs $3 \%$ routinely referring to "Acromegaly Info," respectively, and 14\% vs 5\% routinely referring to "Pituitary Disorders," respectively).

\section{Awareness and referrals by physicians to patient financial support programs}

As previously described, the vast majority of patients currently receiving drug therapy ( $>90 \%$; Figure $1 \mathrm{~A}$ and B) are on octreotide, lanreotide, or pasireotide (alone or in combination with other treatments). The survey inquired about physicians' awareness of financial assistance programs offered by the drug manufacturers. Only $17 \%$ of physicians mention routinely recommending financial resources for patients without publicly funded health care. This increases to $25 \%$ when presented with a list of examples, although $34 \%$ mention being familiar with at least one (though not routinely referring patients to any), and $41 \%$ mention not being familiar with any (Figure 4A and B). There was no significant difference between respondents who believe that patient adherence significantly impacts treatment outcome and those who do not in the proportion who routinely refer patients to at least one program, the proportion familiar with at least one program (though not routinely referring patients to any), and the proportion being familiar with 
A
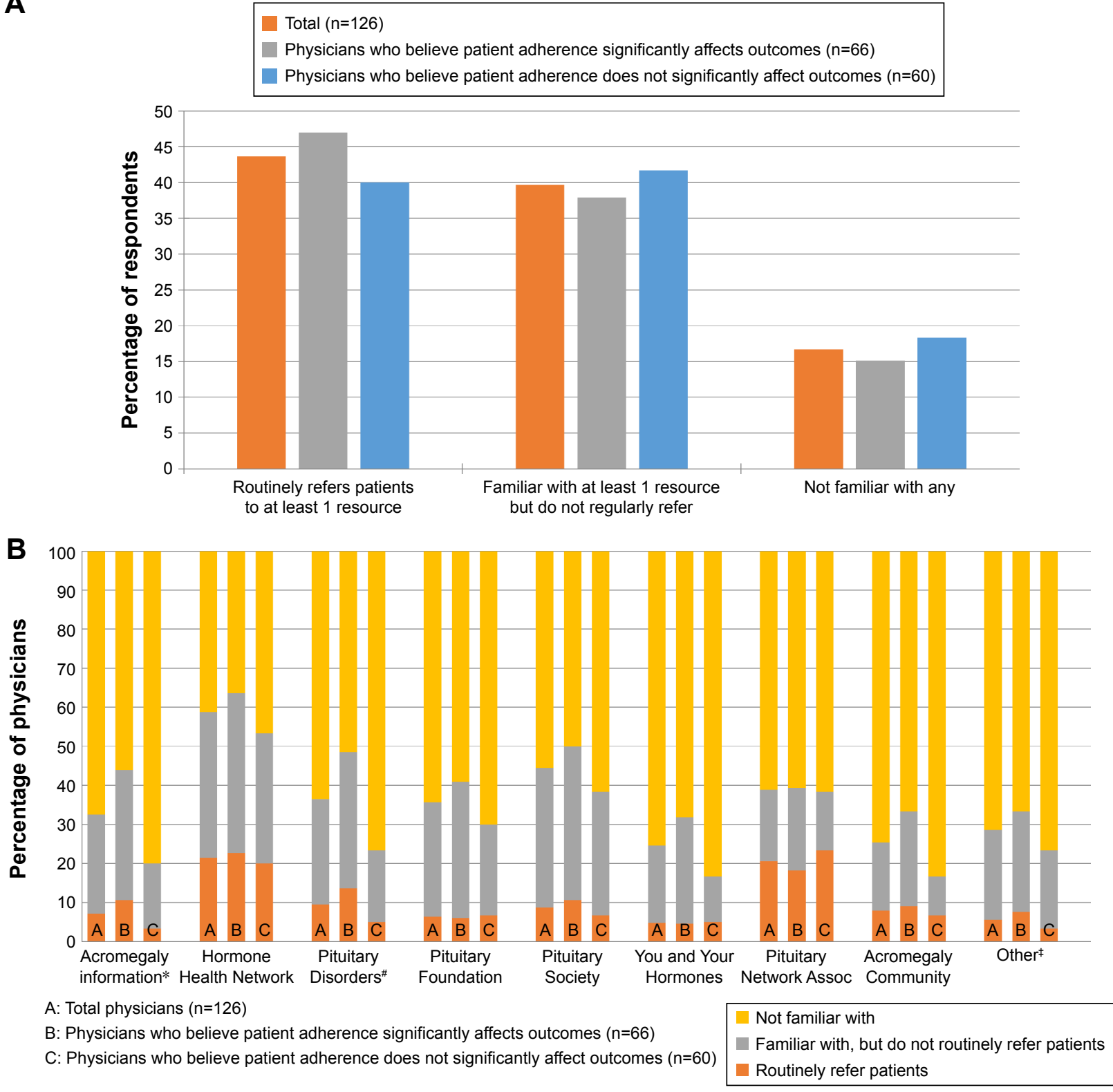

Figure 3 (A) Overall referrals for patient education resources; (B) awareness of and referrals to patient education resources.

Notes: No significant difference between respondents who do and do not believe patient adherence significantly impacts treatment outcome in the proportion who routinely refers patients to at least one program, the proportion familiar with at least one program, and the proportion being familiar with any program, $X^{2}(2, \mathrm{~N}=I 26)=0.654, P=0.72 \mathrm{I}$. *Significant overall difference (chi-square $P=0.015)$ between $B$ and $C$; significant pairwise differences $(P<0.05)$ for "familiar with, but do not routinely refer" and for "not familiar with." "Significant overall difference (chi-square $P=0.012$ ) between B and $C$; significant pairwise differences $(P<0.05)$ for "familiar with, but do not routinely refer" and for "not familiar with." $\neq$ Others: additional support groups and educational resources may be found through the endocrine societies of individual countries/regions. Acromegaly Info (www.acromegalyinfo.com); Hormone Health Network (www.hormone.org); Pituitary Disorders (www.pituitarydisorder.net); Pituitary Foundation (www. pituitary.org.uk); Pituitary Society (www.pituitarysociety.org); You and Your Hormones (http://www.yourhormones.info); Pituitary Network Association (www.pituitary. org); Acromegaly Community (www.acromegalycommunity.com).

any program, $X^{2}(2, \mathrm{~N}=126)=0.214, P=0.898$. There was a significant difference in familiarity with and referrals to information found through endocrine societies $(P=0.004$, Fisher's exact test); physicians who believe that patient adherence has a significant impact on outcomes were more likely to be familiar with these resources compared to those who do not ( $36 \%$ vs $17 \%$, respectively), although there was no difference in routine referrals ( $6 \%$ vs $0 \%$, respectively). Looking specifically at those currently prescribing either octreotide or pasireotide, which are produced by the same manufacturer $(n=107)$, only $13 \%$ routinely referred patients to the manufacturer's program, while $32 \%$ of physicians were aware of it but did not routinely refer patients to it, and 55\% were not familiar with this program. Among those currently 


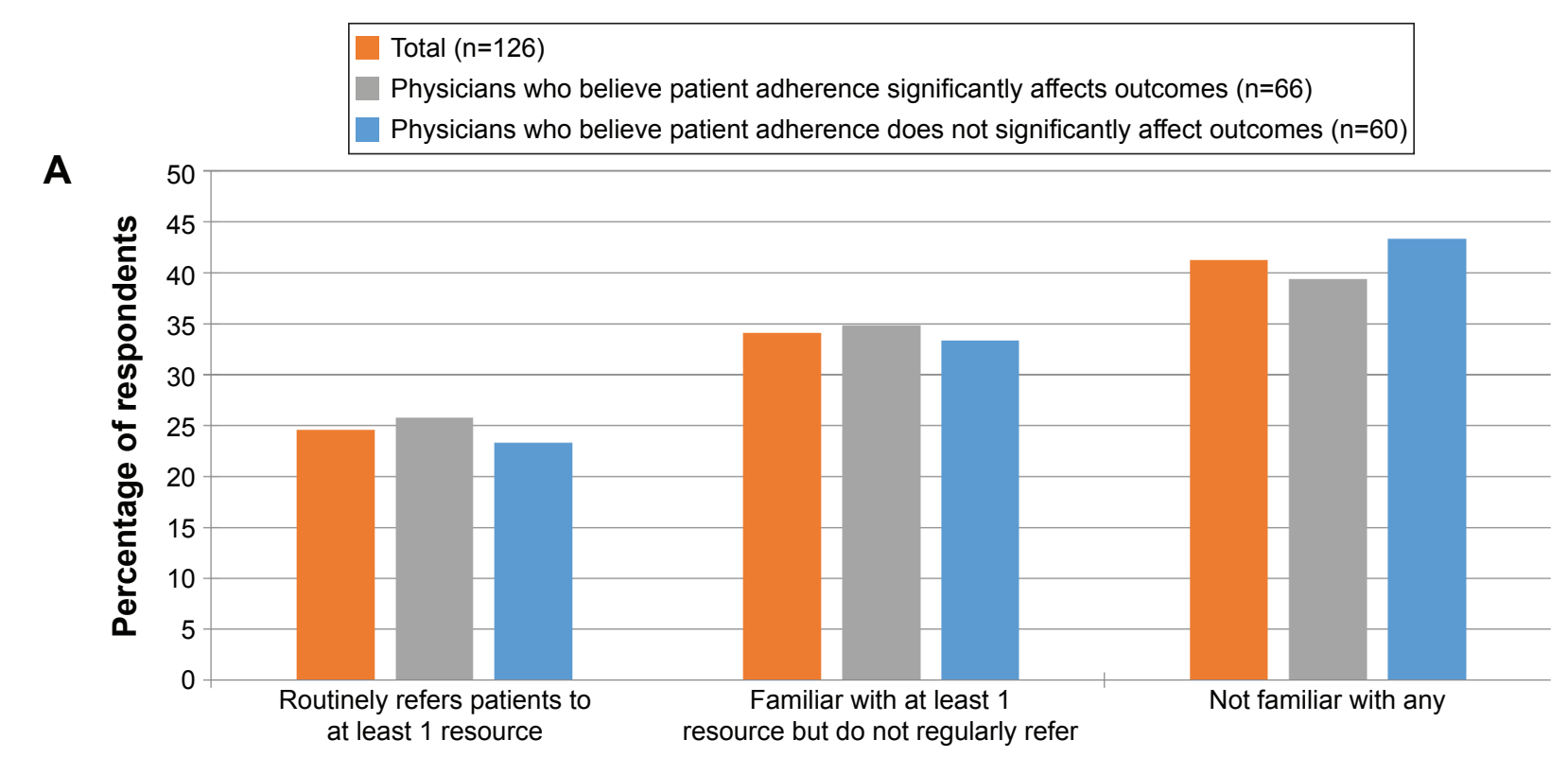

B

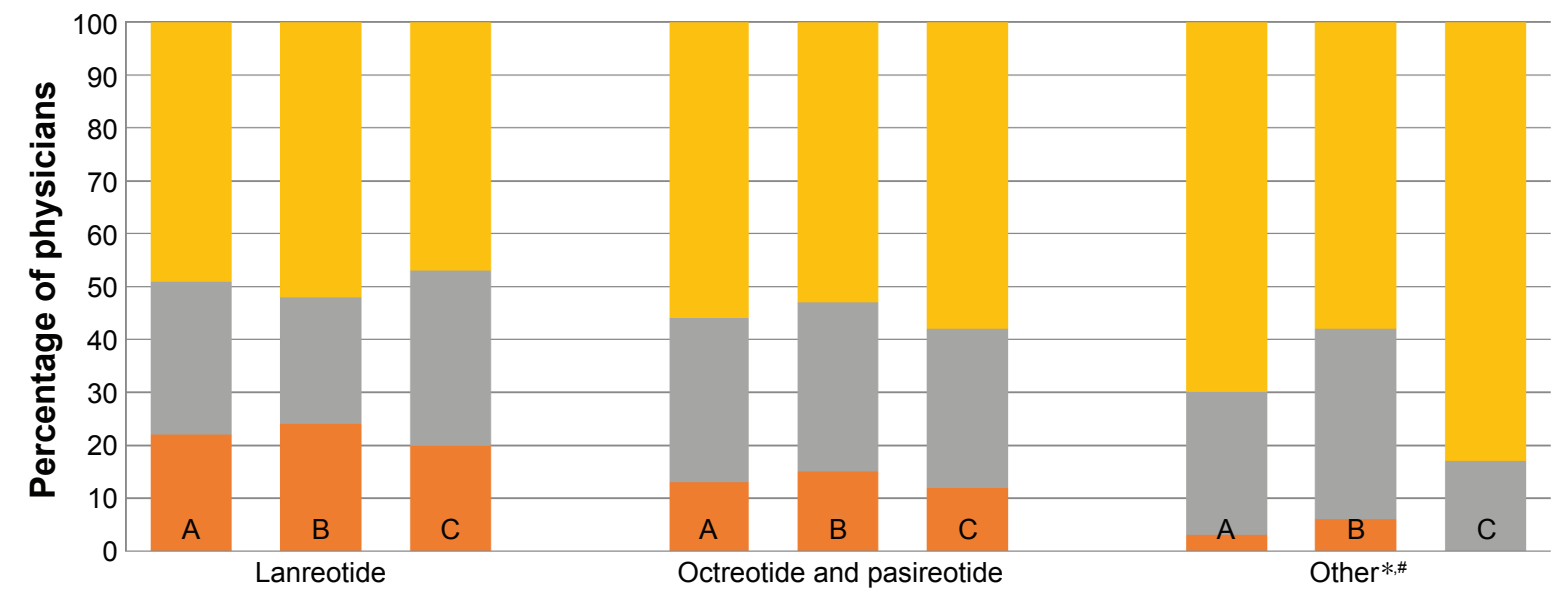

A: Total physicians $(n=126)$

B: Physicians who believe patient adherence significantly affects outcomes $(n=66)$

C: Physicians who believe patient adherence does not significantly affect outcomes $(n=60)$

Not familiar with

Familiar with, but do not routinely refer patients

Routinely refer patients

Figure 4 (A) Overall referrals for patient financial resources; (B) awareness of and referrals to patient financial resources.

Notes: No significant difference between respondents who do and do not believe patient adherence significantly impacts treatment outcome in the proportion who routinely refer patients to at least one program, the proportion familiar with at least one program (though not routinely referring patients to any), and the proportion being familiar with any program, $X^{2}(2, N=126)=0.214, P=0.898$. *Others: additional financial information found through the endocrine societies of individual countries/regions. \#Significant overall difference (chi-square $P=0.004)$ between B and C; significant pairwise differences $(P<0.05)$ for "familiar with, but do not routinely refer" and for "not familiar with." Financial assistance for lanreotide (http://acromegaly.somatulinedepot.com/resources/copay-savings-programs); Financial assistance for octreotide and pasireotide ( I-877-LAR-IN FO, peak Pituitary Education, Access, and Knowledge, www.endocrineaccessnow.com).

prescribing lanreotide $(n=69), 29 \%$ routinely referred patients to the financial assistance program offered by the manufacturer, while $35 \%$ were aware but did not refer patients, and $36 \%$ were not familiar with this program.

\section{Discussion}

Patients with acromegaly face a significant burden from the symptoms and complications of the disease itself; this burden can be further increased by the need for chronic therapy. In this study, the majority $(70 \%)$ of patients were currently on treatment, and the vast majority $(>90 \%)$ of those patients were prescribed SSAs or pegvisomant. Recent claims database studies have also reported SSAs and pegvisomant (collectively) among the most common treatments. ${ }^{8,20,21}$ All of these treatments are injectable therapies, which can be associated with various patient concerns ${ }^{18}$ and difficulties in terms of side effects, adherence, and overall impact on QoL; ${ }^{4}$ these treatments are also associated with substantial costs. ${ }^{7,8}$ Thus, adherence to therapy with these commonly prescribed treatments may be challenging for patients. 
About half of the respondents indicated that they were very or extremely satisfied with the efficacy ( $48 \%)$ and safety $(56 \%)$ of currently available treatments, and about half of the respondents $(52 \%)$ indicated that they believe patient treatment adherence has a significant impact on treatment outcomes. Data regarding treatment adherence and outcomes specific to acromegaly are scarce, although one registry study reported that nonadherence accounted for $\sim 20 \%$ of patients with uncontrolled disease. ${ }^{22}$ There is also evidence suggesting a need for improved adherence to follow-up and monitoring; ${ }^{23}$ patients may not be aware of the need for follow-up ${ }^{24}$ or may think treatment and/or follow-up are unnecessary due to an absence of subjective symptoms, ${ }^{16}$ and the inability to closely monitor patients seems to be associated with a lower rate of treatment and high rate of active disease. ${ }^{16,23,24}$ From a broader perspective, an association between adherence to therapy and treatment outcomes has been demonstrated in multiple disease states, including chronic diseases ${ }^{25-31}$ suggesting the same would be true in acromegaly. Although, a recent study using a web-based survey of health care providers with experience in treating acromegaly $(n=23)$ found that $75 \%$ were concerned about adherence to pharmacotherapy and identified inconvenience of treatment and financial issues as being among the top barriers to adherence from the provider perspective. ${ }^{32}$ The results of this study suggest that it is necessary to increase awareness of the importance of treatment adherence among physicians who treat patients with acromegaly.

Effective communication with patients has been shown to improve medication adherence, ${ }^{33}$ and for patients with acromegaly, discussions regarding the diagnosis, patient concerns, treatment and treatment goals, and available resources (such as the ones included in the survey) may help to address potential barriers to adherence ${ }^{34,35}$ and improve the overall treatment experience. ${ }^{18}$ Indeed, offering counseling and informing newly diagnosed patients about the acromegaly community are valued by patients. ${ }^{17}$ In this study, approximately two thirds of respondents indicated that they discuss a patient's support structure. However, only about one third of their patients speak with a nurse the same day they are diagnosed, respondents (or their dedicated nurses) discuss tools such as adherence reminders with about half of patients, and less than half of respondents routinely refer patients to patient education and support resources. Despite the large percentage of patients for whom respondents prescribed medications that have a financial assistance program offered by the manufacturer (ie, SSAs), only $25 \%$ of respondents routinely refer patients to financial resources, and $41 \%$ indicated they were not familiar with any of these resources. The finding that there was no significant difference between respondents who believe patient adherence significantly impacts treatment outcome and those who do not in the proportion who routinely refer patients to at least one program or are familiar with at least one program indicates a need to increase awareness among physicians of the different resources available to patients and how patients, nurses, and physicians can collaborate for successful treatment experiences (eg, using approaches described by Plunkett and Barkan). ${ }^{18}$

Limitations of this study include possible enrollment bias (participants could be a selected group and not necessarily representative of all endocrinologists) and inherent limitations of self-reported data. Because the survey did not inquire about treatment outcomes, it is not known whether patient treatment outcomes differed depending on whether respondents do or do not discuss and refer patients to the various resources included. The study did not specifically address treatment adherence rates or potential barriers to adherence observed in the respondents' practices. The survey did not gather information regarding a respondent's rationale for not discussing various topics (eg, adherence reminders) or for not referring patients to a support resource that they were familiar with; as such, whether respondents believe the resources are reliable or helpful is not clear. The specific resources included in the survey may not represent a comprehensive list of all resources available, and the degree to which patients find these particular resources useful is not known.

\section{Conclusion}

The results of this study suggest an unmet need for increased awareness among endocrinologists with respect to the importance of patient adherence to therapy and the availability of education, support, and financial resources for patients with acromegaly. Additional research is needed to understand which resources patients identify as most helpful, to evaluate barriers to adherence and the effect of utilization of patient resources and medication/disease management tools on treatment adherence, and to quantify the impact of adherence on treatment outcomes for patients with acromegaly.

\section{Acknowledgments}

The authors thank Sherri D Jones, PharmD of MedVal Scientific Information Services, LLC, for providing medical writing and editorial assistance. This manuscript was prepared according to the International Society for Medical Publication Professionals' "Good Publication Practice for Communicating Company-Sponsored Medical 
Research: The GPP3 Guidelines." This work was supported by Deerfield Institute, and the preparation of this manuscript was funded by Deerfield Institute to MedVal Scientific Information Services, LLC, Skillman, NJ, USA.

\section{Author contributions}

All the authors contributed equally and each was involved in study design, data acquisition, or data analysis/interpretation and in drafting or critically revising the manuscript. All the authors reviewed the final manuscript and gave approval for submission.

\section{Disclosure}

SPB and DG are employees of Deerfield Institute. The authors report no other conflicts of interest in this work.

\section{References}

1. Melmed S. Medical progress: acromegaly. N Engl J Med. 2006; 355(24):2558-2573.

2. Melmed S. Acromegaly pathogenesis and treatment. JClin Invest. 2009; 119(11):3189-3202.

3. Rowles SV, Prieto L, Badia X, Shalet SM, Webb SM, Trainer PJ. Quality of life (QOL) in patients with acromegaly is severely impaired: use of a novel measure of QOL: acromegaly quality of life questionnaire. J Clin Endocrinol Metab. 2005;90(6):3337-3341.

4. Strasburger CJ, Karavitaki N, Stormann S, et al. Patient-reported outcomes of parenteral somatostatin analogue injections in 195 patients with acromegaly. Eur J Endocrinol. 2016;174(3):355-362.

5. Colao A, Ferone D, Marzullo P, Lombardi G. Systemic complications of acromegaly: epidemiology, pathogenesis, and management. Endocr Rev. 2004;25(1):102-152.

6. Melmed S, Casanueva FF, Klibanski A, et al. A consensus on the diagnosis and treatment of acromegaly complications. Pituitary. 2013; 16(3):294-302.

7. Placzek H, Xu Y, Mu Y, Begelman SM, Fisher M. Clinical and economic burden of commercially insured patients with acromegaly in the United States: a retrospective analysis. J Manag Care Spec Pharm. 2015; 21(12):1106-1112.

8. Broder MS, Neary MP, Chang E, Cherepanov D, Katznelson L. Treatments, complications, and healthcare utilization associated with acromegaly: a study in two large United States databases. Pituitary. 2014; 17(4):333-341.

9. Auriemma RS, Galdiero M, De Martino MC, et al. The kidney in acromegaly: renal structure and function in patients with acromegaly during active disease and 1 year after disease remission. Eur JEndocrinol. 2010; 162(6): 1035-1042.

10. Adelman DT, Liebert KJP, Nachtigall LB, Lamerson M, Bakker B. Acromegaly: the disease, its impact on patients, and managing the burden of long-term treatment. Int J Gen Med. 2013;6:31-38.

11. Dekkers OM, Biermasz NR, Pereira AM, Romijn JA, Vandenbroucke JP. Mortality in acromegaly: a metaanalysis. J Clin Endocrinol Metab. 2008;93(1):61-67.

12. Holdaway IM, Rajasoorya RC, Gamble GD. Factors influencing mortality in acromegaly. J Clin Endocrinol Metab. 2004;89(2):667-674.

13. Katznelson L, Laws ER Jr, Melmed S, et al. Acromegaly: an endocrine society clinical practice guideline. JClin Endocrinol Metab. 2014;99(11): 3933-3951.

14. Holdaway IM, Bolland MJ, Gamble GD. A meta-analysis of the effect of lowering serum levels of GH and IGF-I on mortality in acromegaly. Eur J Endocrinol. 2008;159(2):89-95.
15. Ben-Shlomo A, Sheppard MC, Stephens JM, Pulgar S, Melmed S. Clinical, quality of life, and economic value of acromegaly disease control. Pituitary. 2011;14(3):284-294.

16. Kasuki L, Marques NV, Nuez MJ, Leal VL, Chinen RN, Gadelha MR. Acromegalic patients lost to follow-up: a pilot study. Pituitary. 2013; 16(2):245-250.

17. Gurel MH, Bruening PR, Rhodes C, Lomax KG. Patient perspectives on the impact of acromegaly: results from individual and group interviews. Patient Prefer Adherence. 2014;8:53-62.

18. Plunkett C, Barkan AL. The care continuum in acromegaly: how patients, nurses, and physicians can collaborate for successful treatment experiences. Patient Prefer Adherence. 2015;9:1093-1099.

19. Council of American Survey Research Organizations. CASRO ${ }^{\circledR}$. Available from: http://www.casro.org/?page=TheCASROCode2014. Accessed September 29, 2016.

20. Burton T, Le NE, Bancroft T, Neary M. Real-world comorbidities and treatment patterns of patients with acromegaly in two large US health plan databases. Pituitary. 2013;16(3):354-362.

21. Broder MS, Chang E, Ludlam WH, Neary MP, Carmichael JD. Patterns of pharmacologic treatment in US patients with acromegaly. Curr Med Res Opin. 2016;32(5):799-805.

22. Schofl C, Grussendorf M, Honegger J, et al. Failure to achieve disease control in acromegaly: cause analysis by a registry-based survey. Eur J Endocrinol. 2015;172(4):351-356.

23. Silverstein JM. Need for improved monitoring in patients with acromegaly. Endocrine Connections. 2015;4(4):R59-R67.

24. Delemer B, Chanson P, Foubert L, et al. Patients lost to follow-up in acromegaly: results of the ACROSPECT study. Eur J Endocrinol. 2014; 170(5):791-797.

25. DiMatteo MR, Giordani PJ, Lepper HS, Croghan TW. Patient adherence and medical treatment outcomes: a meta-analysis. Med Care. 2002; 40(9):794-811.

26. Ayyagari R, Wei W, Cheng D, Pan C, Signorovitch J, Wu EQ. Effect of adherence and insulin delivery system on clinical and economic outcomes among patients with type 2 diabetes initiating insulin treatment. Value Health. 2015;18(2):198-205.

27. Bluett J, Morgan C, Thurston L, et al. Impact of inadequate adherence on response to subcutaneously administered anti-tumour necrosis factor drugs: results from the Biologics in Rheumatoid Arthritis Genetics and Genomics Study Syndicate cohort. Rheumatology. 2015;54(3): 494-499.

28. Barnes CB, Ulrik CS. Asthma and adherence to inhaled corticosteroids: current status and future perspectives. Respir Care. 2015;60(3): 455-468.

29. Cohen BA, Coyle PK, Leist T, Oleen-Burkey MA, Schwartz M, Zwibel H. Therapy optimization in multiple sclerosis: a cohort study of therapy adherence and risk of relapse. Mult Scler Relat Disord. 2015; $4(1): 75-82$.

30. De Vera MA, Bhole V, Burns LC, Lacaille D. Impact of statin adherence on cardiovascular disease and mortality outcomes: a systematic review. Br J Clin Pharmacol. 2014;78(4):684-698.

31. Menzin J, Caon C, Nichols C, White LA, Friedman M, Pill MW. Narrative review of the literature on adherence to disease-modifying therapies among patients with multiple sclerosis. J Manag Care Pharm. 2013;19(1 Suppl A):S24-S40.

32. Liu S, Xu Y, Begelman SM, Shi L. Barriers to treatment adherence associated with acromegaly in the United States: provider's perspective. Value Health. 2015;18(3):A64.

33. Zolnierek KB, DiMatteo MR. Physician communication and patient adherence to treatment: a meta-analysis. Med Care. 2009;47(8): 826-834.

34. Vermeire E, Hearnshaw H, Van Royen P, Denekens J. Patient adherence to treatment: three decades of research. A comprehensive review. J Clin Pharmacol. 2001;26(5):331-342.

35. Osterberg L, Blaschke T. Adherence to medication. NEngl J Med. 2005; 353(5):487-497. 
Patient Preference and Adherence

Dovepress

\section{Publish your work in this journal}

Patient Preference and Adherence is an international, peer-reviewed, open access journal that focuses on the growing importance of patient preference and adherence throughout the therapeutic continuum. Patient satisfaction, acceptability, quality of life, compliance, persistence and their role in developing new therapeutic modalities and compounds to optimize

Submit your manuscript here: http://www.dovepress.com/patient-preference-and-adherence-journ clinical outcomes for existing disease states are major areas of interest for the journal. This journal has been accepted for indexing on PubMed Central. The manuscript management system is completely online and includes a very quick and fair peer-review system, which is all easy to use. Visit http://www. dovepress.com/testimonials.php to read real quotes from published authors. 